\title{
Choroidal amelanotic melanoma in a patient with oculocutaneous albinism, a case report
}

\author{
Francesca Guido ${ }^{1 *}$, Maria Grazia Fabrini ${ }^{2}$, Federica Cresti $^{1}$ and Federica Genovesi Ebert ${ }^{1}$ \\ ${ }^{1}$ Ophthalmic Surgery Department, University of Pisa, 2 Via Paradisa, Pisa, Italy \\ ${ }^{2}$ Department of Radiotherapy, University of Pisa, 57 Via Roma, Pisa, Italy
}

\begin{abstract}
The aim of this case report is to describe a rare case of jumbo choroidal amelanotic melanoma in a patient with oculocutaneous albinism treated with stereotactic radiotherapy. A 32 years old, Caucasian male, with oculocutaneous albinism, was admitted to our Ocular Oncology Center of Pisa in February 2018. Slit lamp examination of the left eye showed iris transillumination defects and nystagmus. Funduscopic examination revealed a blonde fundus and a poorly pigmented solid lesion that took up the upper half of the vitreous chamber and touched the lens. B-scan and A-scan ultrasound revealed a mushroom shaped lesion that broke through Bruch's membrane measuring $15 \mathrm{~mm}$ in thickness, $8 \mathrm{~mm}$ in basal diameter, low internal reflectivity, and regular structure. The clinical and imaging features suggested a diagnosis of jumbo choroidal amelanotic melanoma. The patient was treated with stereotactic radiotherapy with Volumetric-Modulated Arc Therapy (VMAT) with flattening filter-free (FFF) on a VarianTM TrueBeamSTx, 27 Gy in a single fraction.
\end{abstract}

At the 3-month follow-up visit, the tumor showed an exudative retinal detachment which was treated with an intravitreal injection of bevacizumab. At the 5-month follow-up visit slit lamp examination showed cataract, and iris rubeosis. The tumor demonstrated slight regression from $15 \mathrm{~mm}$ to $12 \mathrm{~mm}$ in thickness. After 17 months from the treatment the lesion was greatly reduced from $12 \mathrm{~mm}$ to $5 \mathrm{~mm}$ in thickness. Regular systemic assessments including abdominal ultrasound and chest $\mathrm{RX}$ were performed and patient was healthy with no signs of systemic metastatic disease.

Although rare patients with oculocutaneous albinism may develop uveal melanoma and stereotactic radiotherapy can represent a valid alternative treatment in jumbo melanoma.

\section{Introduction}

Oculocutaneous albinism (OCA) defines a group of hereditary diseases of the melanin biosynthesis, characterized by a generalized reduction of pigmentation of the hair, skin and eyes and by variable ocular signs, including reduction of visual acuity photophobia and nystagmus [1].

While melanocytic tumors are rare in patients with OCA, that patients have a high risk developing other cutaneous precancerous and cancerous lesions induced by ultraviolet radiation (UVR) like actinic keratosis, squamous cell carcinoma (SCC), and basal cell carcinoma (BCC) $[2,3]$

In the literature only 5 cases of choroidal melanoma have been reported, two of which have been enucleated while the others three cases have been treated with iodine-125 plaque brachytherapy [4-8]. We describe a rare case of jumbo choroidal amelanotic melanoma in a patient with oculocutaneous albinism treated with stereotactic radiotherapy.

\section{Case report}

A 32 years old, Caucasian male, Albanian, with oculocutaneous albinism and with a family history unknown, was admitted to our Ocular Oncology Center of Pisa on February 2018. Slit lamp examination of the left eye showed iris transillumination defects, a solid lesion touching the lens and nystagmus (Figures 1 and 2). Intraocular pressure was $25 \mathrm{mmHg}$ and visual acuity was 20/200.
Funduscopic examination revealed a blonde fundus and a poorly pigmented solid lesion that took up the upper half of the vitreous chamber. B-scan and A-scan Standardized Echography was performed with a 20 and a $10 \mathrm{MHz}$ probe and revealed a mushroom shaped lesion that broke through Bruch's membrane measuring $15 \mathrm{~mm}$ in thickness, $8 \mathrm{~mm}$ in basal diameter (Figure 3); the lesion presented a low internal reflectivity and regular structure (Figure 4).

Fluorescein and indocyanine Angiography showed an irregular hyperfluorescence with atypical circulation (Figure 5). Lesion was partially explorable due to the nystagmus. The clinical and imaging features suggested a diagnosis of jumbo choroidal amelanotic melanoma.

On March 2018 the patient was treated with stereotactic radiotherapy with Volumetric-Modulated Arc Therapy (VMAT) with flattening filter-free (FFF) on a VarianTM TrueBeamSTx, under local anesthesia due to nystagmus. $27 \mathrm{~Gy}$ in a single fraction were delivered.

At the 3-month follow-up visit, the tumor showed an exudative retinal detachment which was treated with an intravitreal injection of

${ }^{\star}$ Correspondence to: Francesca Guido, Ophthalmic Surgery Department, University of Pisa, 2 Via Paradisa, Pisa, Italy, E-mail: francescaguido.oculista@ gmail.com

Key words: albinism, uveal melanoma, stereotactic radiotherapy

Received: May 24, 2020; Accepted: July 10, 2020; Published: July 17, 2020 


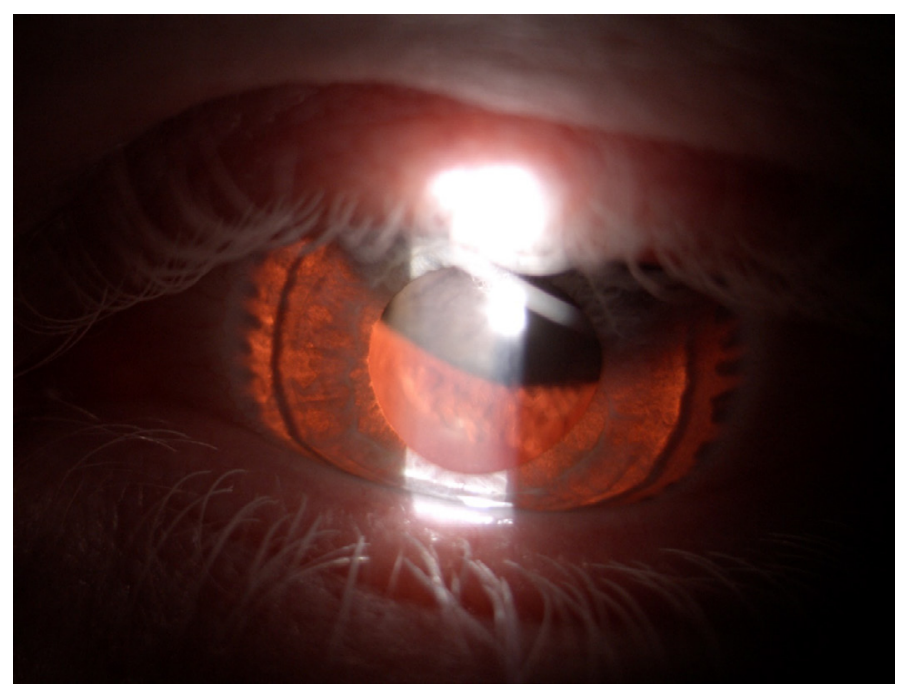

Figure 1. Iris transillumination defect in an albino patient with solid lesion

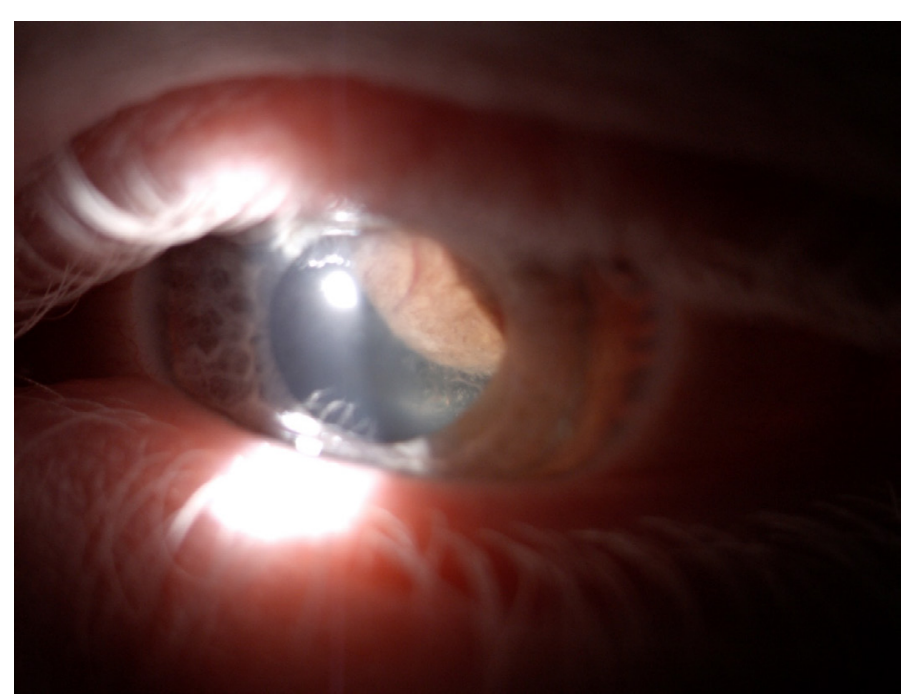

Figure 2. Jumbo amelanotic lesion touching the lens

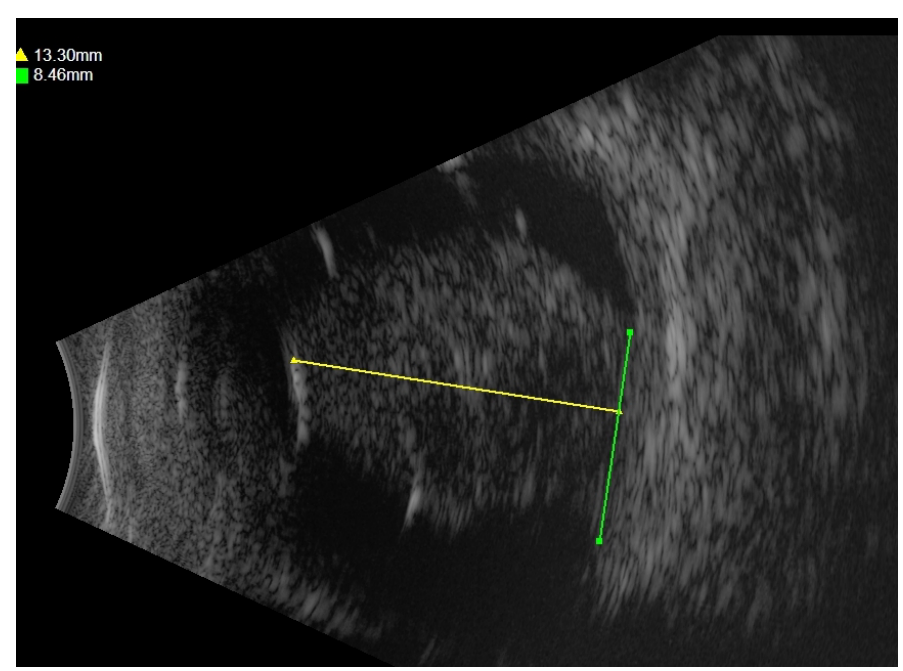

Figure 3. B-scan Ultrasonography. Mushroom shaped lesion that broke through Bruch's membrane

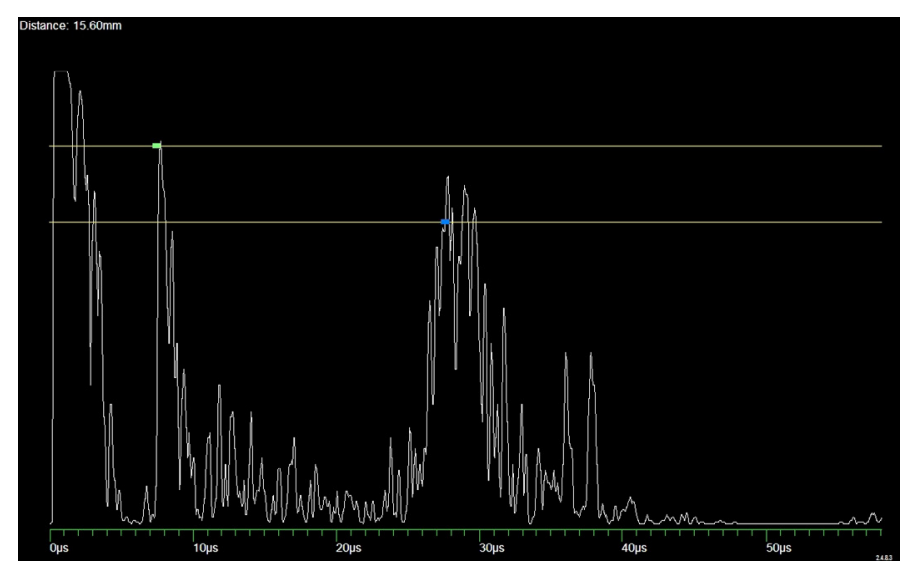

Figure 4. A-scan Standardized Echography. Low internal reflectivity and regular structure

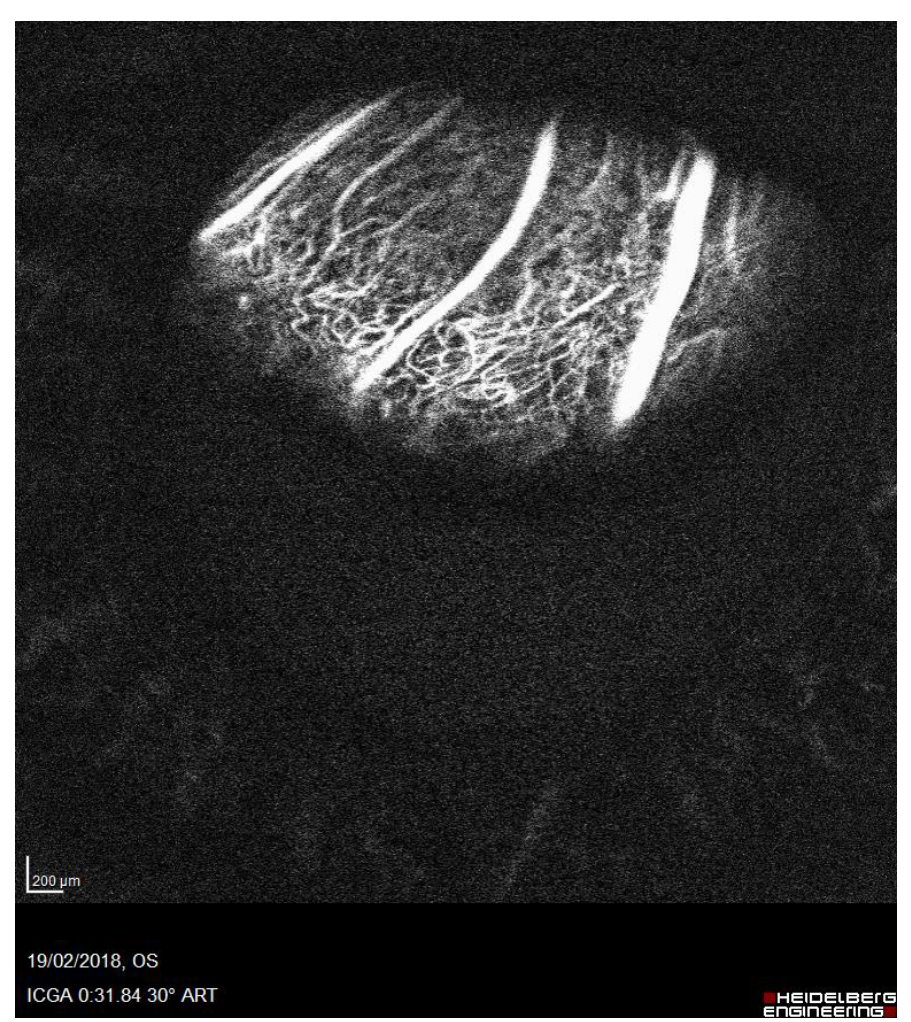

Figure 5. Indocyanine Angiography. Atypical circulation

bevacizumab. At the 5-month follow-up visit slit lamp examination showed cataract and iris rubeosis (Figure 6). Intraocular pressure was under control with topical therapy. B-scan ultrasound revealed a slight tumor regression from $15 \mathrm{~mm}$ to $12 \mathrm{~mm}$ in thickness.

After 17 months from the treatment the tumor was greatly reduced from $12 \mathrm{~mm}$ to $5 \mathrm{~mm}$ in thickness (Figure 7). Regular systemic assessments including abdominal ultrasound and chest RX were performed and patient was healthy with no signs of systemic metastatic disease.

\section{Discussion}

Generalized hypopigmentation or albinism is a rare, autosomal recessive disorder with multiple variant. The most common form is 


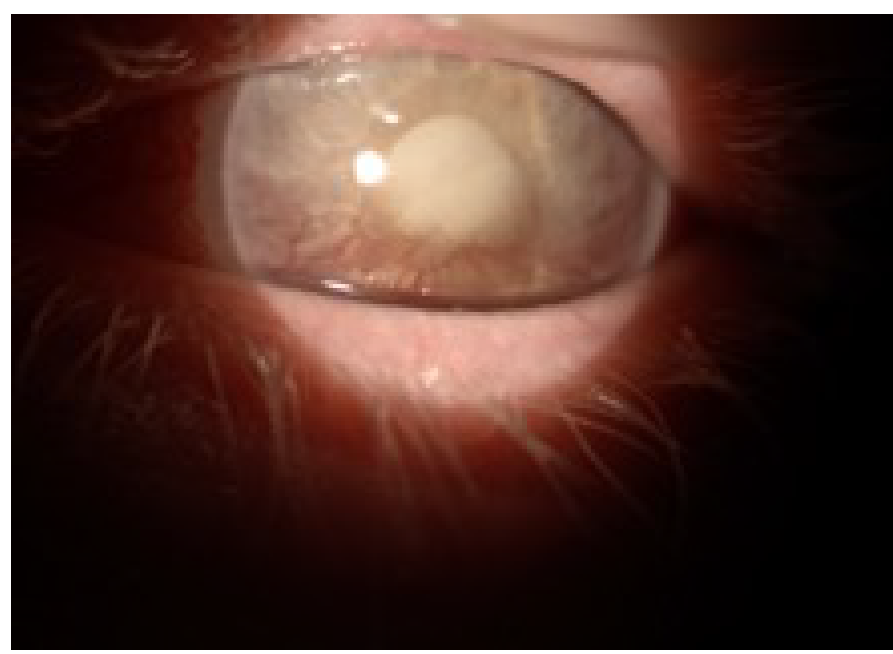

Figure 6. Cataract and iris rubeosis

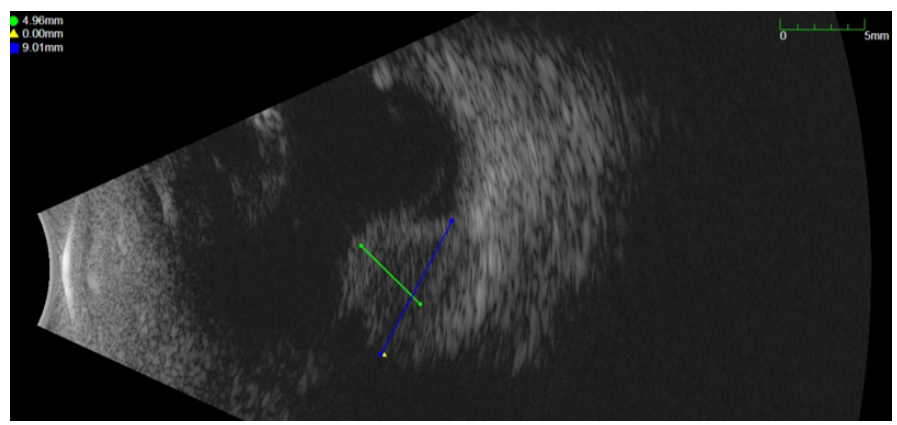

Figure 7. B-scan Ultrasonography. Significant reduction in the thickness of the lesion

oculocutaneous albinism (OCA) in which the eye, hair and skin are involved [9].

The worldwide prevalence of this disorder is 1 cases in 17,000 [1]. OCA is classified and divided into three group. In type 1 albinism the genetic defect is present in the tyrosinase gene; the amount of pigmentation present it is related to the total or partial inactivation of the resulting protein (OCA $1 \mathrm{~A}$ and OCA $1 \mathrm{~B}$ respectively). Type 2 albinism result from mutations in a melanosomal transmembrane protein and in Type 3 the abnormality is present in the gene encoding the tyrosinase relates protein-1 [9].

Albino patients rarely develop cutaneous melanocytic cancers and a majority of the cases described are amelanotic [10,11]. Extremely rare are ocular melanoma with only six cases reported including our case. It is still unknown the reason of this low incidence while it is well established that this patients have a greater risk of other cutaneous lesions induced by UVR, including actinic keratosis, SCC, and BCC $[2,3]$.

None of the 5 cases described in the literature have been treated with Stereotactic photon beam Radiotherapy as we did. The only conservative radiotherapy for Uveal Melanoma (UM) that showed a grade A recommendation (Strong recommendation, high quality evidence) according to Uveal melanoma UK national guidelines is Brachytherapy.

Jumbo melanomas are still a therapeuthical challenge as are unsuitable for brachytherapy: currently stereotactic radiotherapy has been suggested with the grade recommendation $\mathrm{C}$ (Strong recommendation, low quality evidence), as well as Proton beam

\section{Radiotherapy $[12,13]$.}

Dealing with jumbo UM nowadays the grade A recommendation treatment is still enucleation, but this therapeutic option do not improve 5 years overall survival rate [14] and cause a worsening of Quality of life $[15,16]$. Thus stereotactic radiation therapy (SRT) can be proposed for the jumbo UM even if with grade recommendation C. With SRT, photons are focused onto the tumor from different directions, either simultaneously (single shot) or sequentially (hypo-fractionated doses), such that a high dose of radiation is delivered to the lesion while minimizing collateral damage to healthy surrounding tissues [17]. Single shot High-dose radiation resulted in high local tumor control for generally considered radioresistant tumor such as uveal melanoma [18]. We administered a dose of $27 \mathrm{~Gy}$ in a single fraction achieving a good local control even if with complications such as poor visual result, iris rubeosis and cataract as described for large tumors.

In conclusion, although rare, patients with oculocutaneous albinism may develop uveal melanoma and stereotactic radiotherapy can represent an effective treatment option in jumbo melanoma.

\section{Funding}

None.

\section{Conflicts of interest}

The authors declare no conflict of interest, financial or otherwise.

\section{References}

1. Grønskov K, Ek J, Brondum-Nielsen K (2007) Oculocutaneous albinism. Orphanet J Rare Dis 2: 43. [Crossref]

2. Streutker CJ, McCready D, Jimbow K, From L (2000) Malignant melanoma in a patient with oculocutaneous albinism. J Cutan Med Surg 4: 149-152. [Crossref]

3. Okoro AN (1957) Albinism in Nigeria. A clinical and social study. Br J Dermatol 92 485-492. [Crossref]

4. Shields CL, Frey DM, Pagano W, Shields JA (2006) Choroidal melanoma in a patien with oculocutaneous albinoidism. Retina 10: 10. [Crossref]

5. Kheterpal S, Shields JA, Shields CL, De Potter P, Ehya H, et al. (1996) Choroidal melanoma in an African-American albino. Am J Ophthalmol 122: 901-903. [Crossref]

6. Casswell AG, McCartney AC, Hungerford JL (1989) Choroidal malignant melanoma in an albino. Br J Ophthalmol 73: 840-845. [Crossref]

7. Harasymowycz P, Boucher MC, Corriveau C, Gauthier D, Allaire G (2005) Choroidal amelanotic melanoma in a patient with oculocutaneous albinism. Can J Ophthalmol 40: 754-758. [Crossref]

8. Sivalingam MD, Dalvin LA, Shields CL, Mashayekhi A, Shields JA (2019) Amelanotic ciliochoroidal melanoma in a patient with oculocutaneous albinism. Ocul Oncol Pathol 5:182-185. [Crossref]

9. Oetting WS, King RA (1999) Molecular basis of albinism: mutations and polymorphism of pigmentation genes associated with albinism. Hum Mutat 13: 99-115

10. Nishigori C, Yasumizu M, Kawaguchi M, Tomoya Takata, Oiso N, et al. (2015) Malignant skin tumors in patients with oculocutaneous albinism. J Pigment Disord 2.

11. Ihn H, Nakamura K, Abe M, Furue M, Takehara K, et al. (1993) Amelanotic metastatic melanoma in a patient with oculocutaneous albinism. J Am Acad Dermatol 28: 895900. [Crossref]

12. Nag S, Quivey JM, Earle JD, Followill D, Fontanesi J, et al. (2003) The American Brachytherapy Society recommendations for brachytherapy of uveal melanomas. Int $J$ Radiat Oncol Biol Phys 56: 544-555. [Crossref]

13. Kapoor A, Beniwa V, Beniwa S, Mathur H, Kumara HS (2016) Management of uvea tract melanoma: A comprehensive review. J Egypt Natl Canc Inst 28: 65-72. [Crossref]

14. Diener-West M, Earle JD, Fine SL, Hawkins BS, Moy CS, et al. (2001) The COMS randomized trial of iodine 125 brachytherapy for choroidal melanoma, III: Initial mortality findings. COMS Report No. 18. Arch Ophthalmol 119: 969-982. [Crossref] 
15. Damato B, Hope-Stone L, Cooper B, Brown SL, Salmon P, et al. (2018) Patientreported outcomes and quality of life after treatment of choroidal melanoma: A comparison of enucleation versus radiotherapy in 1596 patients. Am J Ophthalmol 193: 230-251. [Crossref]

16. Miniati M, Fabrini MG, Genovesi Ebert F, Mancino M, Maglio A, et al. (2018) Quality of life, depression, and anxiety in patients with uveal melanoma: A review. J Oncol 2018: 5253109
17. Akbaba S, Foerster R, Nicolay NH, Arians N, Bostel T, et al. (2018) Linear acceleratorbased stereotactic fractionated photon radiotherapy as an eye-conserving treatment for uveal melanoma. Radiat Oncol 13: 140.

18. Zelefsky MJ, Greco C, Motzer R, Magsanoc JM, Pei X, et al. (2012) Tumor contro outcomes after hypofractionated and single-dose stereotactic image-guided intensitymodulated radiotherapy for extracranial metastases from renal cell carcinoma. Int $J$ Radiat Oncol Biol Phys 82: 1744-1748.

Copyright: $\odot 2020$ Guido F. This is an open-access article distributed under the terms of the Creative Commons Attribution License, which permits unrestricted use, distribution, and reproduction in any medium, provided the original author and source are credited. 